Año 13.

Revista de Investigación

Núm. 33

Académica sin Frontera

ISSN: 2007-8870

http://revistainvestigacionacademicasinfrontera.com

Recibido el 28 de agosto de 2020. Dictaminado mediante arbitraje favorablemente 7 de diciembre de 2020.

\title{
La Observancia de la Diversidad Funcional e Inclusiva de la Ley General de Educación sus Repercusiones y Políticas En las IES.
}

\section{The Observance of the Functional and Inclusive Diversity of the General Law of Education, its Repercussions and Policies in the IES.}

\author{
Félix Mauro Higuera Sánchez ${ }^{1}$ \\ Álvaro Coronado Gutiérrez ${ }^{2}$ \\ Ana Patricia Higuera Pacheco ${ }^{3}$ \\ Universidad De Sonora Unidad Regional Sur
}

Resumen:

Las organizaciones internacionales y abordan el tema de la inclusión, los cuales versan sobre la igualdad y la equidad de género, es por lo cual han hecho observaciones a las diferentes naciones, y a sus Instituciones de Educación en todos los niveles incluyendo las instituciones de Educación Superior, A pesar de que es un tema que cuenta con muy diversos aspectos, el objetivo de esta ponencia es crear sensibilidad a las Universidades, ya que si bien es cierto tienen autonomía por una ley estatal que las crea no pueden dejar de observar a la constitución y a la nueva Ley General Educación promulgada el 30 de Septiembre del 2019 y con el fin de que incluyan a sus planes de Desarrollo Institucionales y Administrativas, así como también reglamentarias donde se observe en relevancia La Diversidad Funcional e Inclusión en todos los aspectos; el objetivo es el estudio de esta nueva ley y sus consecuencias actuales así como sus repercusiones que deriva de una investigación en proceso es una descripción, análisis y su evolución. Usando como metodología el estudio de la dogmática teórica jurídica

\footnotetext{
${ }^{1}$ https://orcid.org/0000-0001-6055-4361

${ }^{3}$ https://orcid.org/0000-0003-1721-6660
} 
Año 13.

Núm. 33

\title{
http://revistainvestigacionacademicasinfrontera.com
}

Recibido el 28 de agosto de 2020. Dictaminado mediante arbitraje favorablemente 7 de diciembre de 2020.

aplicable de tipo descriptivo y analítico, para lo cual se recurre a las técnicas de investigación documental con fuentes doctrinarias y normativas

Palabras Claves: Diversidad Funcional; Inclusiva: Educación.

\begin{abstract}
International organizations and address the issue of inclusion, which deal with gender equality and equity, which is why they have made observations to different nations, and their Education Institutions at all levels, including Higher Education institutions. Although it is a subject that has very diverse aspects, the objective of this presentation is to create sensitivity to the Universities, since although it is true that they have autonomy due to a state law that creates them, they cannot fail to observe the constitution and to the new General Education Law promulgated on September 30, 2019 and in order to include their Institutional and Administrative Development plans, as well as regulations where Functional Diversity and Inclusion in all aspects is observed in relevance; The objective is the study of this new law and its current consequences as well as its repercussions that derive from an investigation in process is a description, analysis and its evolution. Using as a methodology the study of the applicable legal theoretical dogmatics of a descriptive and analytical type, for which documentary research techniques are used with doctrinal and normative sources.
\end{abstract}

Keywords: Functional Diversity; Inclusive: Education.

\section{Introducción}

En todo el mundo, las personas con discapacidad tienen los peores resultados sanitarios, e inclusive académicos, además de una menor participación económica y las tasas de pobreza más altas que las personas sin discapacidad. En parte, ello es consecuencia de los obstáculos 
Año 13.

Revista de Investigación

Núm. 33

Académica sin Frontera

ISSN: 2007-8870

\section{http://revistainvestigacionacademicasinfrontera.com}

Recibido el 28 de agosto de 2020. Dictaminado mediante arbitraje favorablemente 7 de diciembre de 2020.

que entorpecen el acceso de las personas con discapacidad a servicios que muchos de nosotros consideramos obvios, en particular la salud, la educación, el empleo, el transporte, o la información. Esas dificultades se exacerban en las comunidades menos favorecidas.

El Informe mundial sobre la discapacidad reúne la mejor información disponible sobre la discapacidad con el fin de mejorar la vida de las personas con discapacidad.

Realizando un análisis en temas relativos en cuanto a la educación superior a existido una gran preocupación por organizaciones internacionales como lo son la Comisión Internacional sobre la Educación para el Siglo XXI, la Comisión Mundial de Cultura y Desarrollo, las $44^{\mathrm{a}}$ y $45^{\mathrm{a}}$ reuniones de la Conferencia Internacional de Educación (Ginebra, 1994 y 1996) las resoluciones aprobadas por la Conferencia General de la UNESCO en sus $27^{\mathrm{a}}$ y $29^{\mathrm{a}}$ reuniones, en particular en relación con la Recomendación relativa a la condición del personal docente de la enseñanza superior, la Conferencia Mundial sobre Educación para Todos (Jomtien, Tailandia, 1990), la Conferencia de las Naciones Unidas sobre el Medio Ambiente y el Desarrollo (Río de Janeiro, 1992), la Conferencia sobre libertad académica y autonomía universitaria (Sinaí, 1992), la Conferencia Mundial de Derechos Humanos (Viena, 1993), la Cumbre Mundial sobre Desarrollo Social (Copenhague, 1995), la Cuarta Conferencia de las Naciones Unidas sobre la Mujer (Beijing, 1995), el Segundo Congreso Internacional sobre Educación e Informática (Moscú, 1996), el Congreso Mundial sobre Educación Superior y Desarrollo de los Recursos Humanos en el Siglo XXI (Manila, 1997), la Quinta Conferencia Internacional de Educación de las Personas Adultas (Hamburgo, 1997) y, en especial, la Agenda para el Futuro, en cuyo Tema 2 (Mejorar las condiciones y la calidad de la educación de adultos) entre otros. 
Año 13.

Revista de Investigación

Núm. 33

Académica sin Frontera

ISSN: 2007-8870

\section{http://revistainvestigacionacademicasinfrontera.com}

Recibido el 28 de agosto de 2020. Dictaminado mediante arbitraje favorablemente 7 de diciembre de 2020.

\section{Material y Método}

De acuerdo con la Conferencia Mundial Sobre La educación Superior, (1998), los cuales son coincidentes de en pronosticar que se observa una creciente demanda de la educación superior sin precedentes, acompañada de una gran diversificación de la misma, y una mayor toma de conciencia de la importancia fundamental que este tipo de educación reviste para el desarrollo sociocultural y económico y para la construcción del futuro, de cara al cual las nuevas generaciones deberán estar preparadas con nuevas competencias y nuevos conocimientos e ideales. La educación superior comprende "todo tipo de estudios, de formación o de formación para la investigación en el nivel postsecundario, impartidos por una universidad $\mathrm{u}$ otros establecimientos de enseñanza que estén acreditados por las autoridades competentes del Estado como centros de enseñanza superior”. La educación superior se enfrenta a todas partes a desafíos y dificultades relativos a la financiación, la igualdad de condiciones de acceso a los estudios y en el transcurso de los mismos, una mejor capacitación del personal, la formación basada en las competencias, la mejora y conservación de la calidad de la enseñanza, la investigación y los servicios, la pertinencias de los programas, las posibilidades de empleo de los diplomados, el establecimiento de acuerdos de cooperación eficaces y la igualdad de acceso a los beneficios que reporta la cooperación internacional. La educación superior debe hacer frente a la vez a los retos que suponen las nuevas oportunidades que abren las tecnologías, que mejoran la manera de producir, organizar, difundir y controlar el saber y de acceder al mismo. Deberá garantizarse un acceso equitativo a estas tecnologías en todos los niveles de los sistemas de en enseñanza. 
Año 13.

Revista de Investigación

Núm. 33

Académica sin Frontera

ISSN: 2007-8870

\section{http://revistainvestigacionacademicasinfrontera.com}

Recibido el 28 de agosto de 2020. Dictaminado mediante arbitraje favorablemente 7 de diciembre de 2020.

Siendo estos lo antecedentes que fincaron el rumbo de los principios para formular los sistemas de educación en nuestra actualidad, bajo unos principios muy simples la cultura de la paz, el respeto a los derechos humanos, la equidad, la justicia.

De la revista Psicología y Mente el Psicólogo Nahum Montagud, (2020) De acuerdo con la Organización Mundial de la Salud (OMS), el término discapacidad abarca deficiencias, limitaciones y restricciones que puede sufrir una persona.

Sin embargo, en los últimos años ha ido ganando más uso el término diversidad funcional, siendo considerado sinónimo de discapacidad, aunque se percibe como políticamente más correcto.

Así pues, en relación con la definición dada por la OMS, se entiende que la diversidad funcional implica problemas que afectan a la estructura corporal, limitaciones para llevar a cabo acciones cotidianas y dificultades para mantener relaciones sociales con los iguales.

Antes de incidir con mayor profundidad sobre los diferentes tipos de diversidad funcional, cabe tratar tres conceptos que se encuentran englobados dentro de este concepto:

Deficiencia

Pérdida de una estructura o función, ya sea mental o física.

Discapacidad

Restricción o ausencia total de una determinada actividad.

Minusvalía

Situación desventajosa consecuencia de una deficiencia o discapacidad que supone afectación en la vida diaria. 
Año 13.

Revista de Investigación

Núm. 33

Académica sin Frontera

ISSN: 2007-8870

\section{http://revistainvestigacionacademicasinfrontera.com}

Recibido el 28 de agosto de 2020. Dictaminado mediante arbitraje favorablemente 7 de diciembre de 2020.

\section{Diversidad Funcional}

Los autores ROMAÑACH \& MANUEL, (2018) hacen una distinción de la definición Manifestando El término mujeres y hombres con diversidad funcional es novedoso y se propuso y empezó a utilizar en el Foro de Vida Independiente en enero de 2005. Entendemos que es la primera vez en la historia y en el mundo que se propone un cambio hacia una terminología no negativa sobre la diversidad funcional, y que esa propuesta parte exclusivamente de las mujeres y hombres con diversidad funcional.

El término consta de cuatro palabras, y eso lo hace a priori más complejo de utilizar que el término que pretende sustituir: personas con discapacidad. No obstante, la experiencia ha demostrado que, en muy poco tiempo, las mujeres y hombres que aceptan el término lo utilizan tanto en forma escrita como hablada con fluidez y naturalidad, habiéndose incluso acuñado el acrónimo PDF, extraído de las iniciales de cada palabra (Persona con Diversidad Funcional).

El uso de la palabras "mujeres y hombres con" mantiene la tradición anterior de reforzar el concepto de que somos mujeres y hombres y, por lo tanto, tenemos y queremos reforzar la dignidad inherente a nuestra esencia como seres humanos que nacemos y queremos vivir con los mismos derechos y dignidad que todos los demás, tal como lo establece la ONU: "Todos los seres humanos nacen libres e iguales en dignidad y derechos y, dotados como están de razón y conciencia, deben comportarse fraternalmente los unos con los otros".

La palabra "diversidad" viene definida en Diccionario de la Real Academia de la lengua como: diversidad. (Del lat. diversǐtas,-ātis). 
Año 13.

Revista de Investigación

Núm. 33

Académica sin Frontera

ISSN: 2007-8870

\section{http://revistainvestigacionacademicasinfrontera.com}

Recibido el 28 de agosto de 2020. Dictaminado mediante arbitraje favorablemente 7 de diciembre de 2020.

1. f. Variedad, desemejanza, diferencia.

Con esa palabra queremos reflejar exactamente eso, la diferencia, la desemejanza con lo que es habitual en la mayoría estadística de la especie humana.

La palabra "funcional" viene definida como:

funcional. 1. adj. Perteneciente o relativo a las funciones

En esta palabra utilizamos la primera acepción de la palabra función:

función. (Del lat. functīo,-ōnis).

1. f. Capacidad de actuar propia de los seres vivos y de sus órganos, y de las máquinas o instrumentos.

Y nos referimos en concreto a los dos primeros conceptos: a las funciones de los órganos o partes de nuestro cuerpo (P. Ej. ojos, oídos, piernas, cerebro, etc.) y también a las funciones que realizamos habitualmente los seres humanos como seres vivos (por ejemplo, desplazarse, ver, comunicarse, etc.).

Como podemos observar, el término es semánticamente correcto en la lengua castellana y recoge todos los conceptos que queremos expresar, a excepción de la discriminación. No obstante, la tradicional vinculación entre la diversidad humana y la discriminación social hace que no resulte necesaria la inclusión de este aspecto en la definición del término, ya que luchamos por que llegue un tiempo en el que la discriminación desaparezca y la diversidad funcional sea aceptada como una riqueza más dentro de la diversidad de la especie humana. 
Año 13.

Revista de Investigación

Núm. 33

Académica sin Frontera

ISSN: 2007-8870

\section{http://revistainvestigacionacademicasinfrontera.com}

Recibido el 28 de agosto de 2020. Dictaminado mediante arbitraje favorablemente 7 de diciembre de 2020.

De lo cual concluyen; La manera en la que desde el Foro de Vida Independiente proponemos denominar a ese colectivo, al que pertenecemos, es mujeres y hombres con diversidad funcional, ya que entendemos que es la primera denominación de la historia en la que no se da un carácter negativo ni médico a la visión de una realidad humana, y se pone énfasis en su diferencia o diversidad, valores que enriquecen al mundo en que vivimos.

Como se ha mencionado los organismos internacionales han observado y criticado principalmente unas de las grandes problemáticas en nuestra actualidad como lo es están convencidos como se desprende de la Conferencia Mundial Sobre La Educación Superior, (1998) de que la educación es uno de los pilares fundamentales de los derechos humanos, la democracia, el desarrollo sostenible y la paz, por lo que deberá ser accesible para todos a lo largo de toda la vida, y de que se necesitan medidas para asegurar la coordinación y cooperación entre los diversos sectores y dentro de cada uno de ellos y, en particular, entre la educación general, técnica y profesional secundaria y postsecundaria, así como entre universidades, escuelas universitarias e instituciones técnicas.

A lo cual son conscientes de que el próximo siglo la educación superior debe tener como fin la mejora de su calidad y su pertinencia y la manera de resolver las principales dificultades que la acechan exigen la firme participación no sólo de gobiernos e instituciones de educación superior, sino también de todas las partes interesadas, comprendidos los estudiantes y sus familias, los profesores, el mundo de los negocios y la industria, los sectores público y privado de la economía, los parlamentos, los medios de comunicación, la comunidad, las asociaciones profesionales y la sociedad, y exigen igualmente que las instituciones de educación superior asuman mayores responsabilidades para con la sociedad y rindan cuentas sobre la utilización de los recursos públicos y privados, nacionales o internacionales. 
Año 13.

Revista de Investigación

Núm. 33

Académica sin Frontera

ISSN: 2007-8870

\section{http://revistainvestigacionacademicasinfrontera.com}

Recibido el 28 de agosto de 2020. Dictaminado mediante arbitraje favorablemente 7 de diciembre de 2020.

De acuerdo con las Naciones Unidas manifiesta un análisis de las Personas con Discapacidad en su Departamento de Asuntos Económicos y Sociales Naciones Unidas, (2015) mismo análisis que realiza una clasificación en los siguientes rubros.

Panorama general.

Alrededor del 10\% de la población mundial, o sea 650 millones de personas, vive con una discapacidad. Constituyen la mayor minoría del mundo.

Esta cifra está aumentando debido al crecimiento de la población, los avances de la medicina y el proceso de envejecimiento, dice la Organización Mundial de la Salud (OMS).

En los países donde la esperanza de vida es superior a los 70 años, en promedio alrededor de 8 años o el $11.5 \%$ de la vida de un individuo transcurre con incapacidades.

El $80 \%$ de las personas con discapacidad vive en países en desarrollo, según el Programa de las Naciones Unidas para el Desarrollo (PNUD)

En los países de la Organización para la Cooperación y el Desarrollo Económicos (OCDE), las tasas de discapacidades son notablemente más altas entre los grupos con menores logros educacionales. El promedio es de 19\%, en comparación con 11\% entre los que tienen más educación.

En la mayoría de los países de la OCDE, se informa de que las mujeres tienen una incidencia más alta de discapacidades que los hombres.

El Banco Mundial estima que el $20 \%$ de los más pobres del mundo tienen discapacidades, y tienden a ser considerados dentro de sus propias comunidades como las personas en situación más desventajosa. 
Año 13.

Núm. 33
Revista de Investigación Académica sin Frontera ISSN: 2007-8870

\section{http://revistainvestigacionacademicasinfrontera.com}

Recibido el 28 de agosto de 2020. Dictaminado mediante arbitraje favorablemente 7 de diciembre de 2020.

Se reconoce que las mujeres con discapacidad experimentan múltiples desventajas, siendo objeto de exclusión debido a su género y a su discapacidad.

Las mujeres y las niñas con discapacidad son particularmente vulnerables al abuso. Según una pequeña encuesta realizada en Orissa (India), prácticamente todas las mujeres y las niñas con discapacidad eran objeto de palizas en el hogar, el 25\% de las mujeres con discapacidades intelectuales habían sido violadas y el 6\% de las mujeres con discapacidad habían sido esterilizadas por la fuerza.

Según el UNICEF, el 30\% de los jóvenes de la calle tienen discapacidad.

La mortalidad correspondiente a los niños con discapacidad puede alcanzar hasta un $80 \%$ en los países en los que la mortalidad de menores de cinco años en su totalidad ha disminuido por debajo del 20\%, dice el Departamento de Desarrollo Internacional del Reino Unido, añadiendo que en algunos casos parecería que se está "eliminando" a esos niños.

Los estudios comparativos sobre la legislación en materia de discapacidad indican que sólo 45 países cuentan con leyes contra la discriminación y otro tipo de leyes específicas a ese respecto.

En el Reino Unido, el 75\% de las empresas del FTSE 100 Índex que figuran en la Bolsa de Comercio de Londres no llegan al nivel básico de accesibilidad de la web, perdiendo en esa forma más de 147 millones de dólares de ingresos.

\section{Educación.}

Según la UNESCO, el 90\% de los niños con discapacidad no asiste a la escuela. 
Año 13.

Revista de Investigación

Núm. 33

Académica sin Frontera

ISSN: 2007-8870

\section{http://revistainvestigacionacademicasinfrontera.com}

Recibido el 28 de agosto de 2020. Dictaminado mediante arbitraje favorablemente 7 de diciembre de 2020.

La tasa mundial de alfabetización de adultos con discapacidad llega solamente al 3\%, y al 1\% en el caso de las mujeres con discapacidad, según un estudio del PNUD de 1998.

En los países de la OCDE, los estudiantes con discapacidad siguen estando subrepresentados en la enseñanza superior, pese a que su número va en aumento, según la OCDE.

Empleo.

Según se estima, unos 386 millones de las personas en edad de trabajar son discapacitadas, dice la Organización Internacional del Trabajo (OIT). El desempleo alcanza hasta un $80 \%$ en algunos países. A menudo los empleadores suponen que las personas con discapacidad no pueden trabajar.

Aunque las personas con discapacidad constituyen un 5 o $6 \%$ significativo de la población de la India, sus necesidades de empleo siguen sin atenderse, dice un estudio del Centro Nacional de Promoción del Empleo para las Personas con discapacidad, pese a la Ley relativa a las "Personas con Discapacidad", que les reserva el 3\% de los empleos gubernamentales. De cerca de 70 millones de personas con discapacidad en la India, sólo alrededor de 100.000 han logrado obtener empleo en la industria.

En una encuesta realizada en los Estados Unidos en 2004 se descubrió que sólo el $35 \%$ de las personas con discapacidad en edad de trabajar están realmente trabajando, en comparación con el $78 \%$ de las que no sufren discapacidades. Dos tercios de los desempleados con discapacidad que respondieron dijeron que les gustaría trabajar pero que no podían encontrar empleo. 
Año 13.

Núm. 33
Revista de Investigación Académica sin Frontera ISSN: 2007-8870

\section{http://revistainvestigacionacademicasinfrontera.com}

Recibido el 28 de agosto de 2020. Dictaminado mediante arbitraje favorablemente 7 de diciembre de 2020.

En un estudio de 2003 realizado por la Universidad de Rutgers se encontró que las personas con discapacidad física y mental están enormemente subrepresentadas en el lugar de trabajo en los Estados Unidos. La tercera parte de los empleadores encuestados dijo que las personas con discapacidad no podían cumplir eficazmente las tareas requeridas. La segunda razón más común para no contratar a las personas con discapacidad era el temor al costo de las comodidades necesarias.

Una encuesta de empleadores realizada en los Estados Unidos en 2003 indicó que el costo de las instalaciones necesarias era solamente de $\$ 500$ o menos; el $73 \%$ de los empleadores informó de que sus empleados no requerían comodidades especiales.

Las empresas informaron de que los empleados con discapacidad tenían mejores tasas de retención en el empleo, reduciendo el alto costo de cambio de personal, según un estudio realizado en los Estados Unidos en 2002. Otras encuestas estadounidenses revelaron que después de un año de empleo, la tasa de retención de personas con discapacidad es del 85\%.

Miles de personas con discapacidad han tenido éxito como dueños de pequeñas empresas, según el Departamento de Trabajo de los Estados Unidos. El censo nacional de 1990 reveló que las personas con discapacidad tienen una tasa más alta de empleo por cuenta propia y de experiencia en pequeñas empresas (12.2\%) que las personas sin discapacidad $(7.8 \%)$.

Violencia.

Por cada niño que muere en zonas de guerra, tres resultan heridos y con discapacidad permanentemente. Según la OMS, en algunos países, hasta una cuarta parte de las discapacidades son resultado de heridas y violencia. 
Año 13.

Revista de Investigación

Núm. 33

Académica sin Frontera

ISSN: 2007-8870

\section{http://revistainvestigacionacademicasinfrontera.com}

Recibido el 28 de agosto de 2020. Dictaminado mediante arbitraje favorablemente 7 de diciembre de 2020.

Las personas con discapacidad tienen más probabilidades de ser víctimas de la violencia o la violación, según un estudio británico de 2004, y menos probabilidades de obtener la intervención de la policía, protección jurídica o cuidados preventivos.

Las investigaciones indican que la violencia contra los niños con discapacidad ocurre a tasas anuales por lo menos 1.7 veces mayores que en el caso de sus pares no discapacitados.

En los últimos años, en América Latina se han hecho más fuertes las observaciones iniciando con los infantes a una educación de calidad, por lo cual se requiere que los sistemas educativos y su infraestructura cuenten con una equidad de acceso, en recursos materiales y físicos de igual manera que la educación sea relevante y pertinente con su entorno social.

En el plano curricular se requiere que sus diseños sean abiertos y flexibles a la vez que sean enriquecidos en los diferentes niveles en función de las necesidades educativas del alumnado, tal y como lo señala la UNESCO, lograr que el aprendizaje sea pertinente para todos exige una transformación profunda de las prácticas educativas, transitando desde una pedagogía de la homogeneidad hacia una pedagogía de la diversidad. Esto es aún un desafío para los países de la región.

Si bien es cierto se reconocen que existen grandes brechas en los diferentes niveles de educación a los que afectan a los grupos de personas que por tradición son excluidos como mujeres, población indígena, personas afrodescendientes, migrantes y refugiados, entre otros. Otro grupo son los que viven con algún tipo de discapacidad física y/o cognitiva, siendo si situación más complicada, ya que en la mayoría de los centros educativos de todos los noveles; no cuentan con las facilidades físicas, tecnológicas para este último grupo, así como también las instituciones de educación superior, los cuales no han propuesto en sus planes de desarrollo institucional el observar un rubro específico para estos grupos. 
Año 13.

Núm. 33
Revista de Investigación Académica sin Frontera ISSN: 2007-8870

\section{http://revistainvestigacionacademicasinfrontera.com}

Recibido el 28 de agosto de 2020. Dictaminado mediante arbitraje favorablemente 7 de diciembre de 2020.

Otro grupo de personas que se destaca son los que por sus características las desigualdades, la estigmatización y las discriminaciones relacionadas con el nivel de ingresos, el género, la etnia, el idioma, el lugar de residencia y la discapacidad están retrasando los progresos hacia una Educación incluyente, dicha situación de agudizado con las personas que son de comunidades pobres y de difícil acceso a las señales de internet, computación y telefonía, teniendo la observancia esta actualidad que ha afectado a todos los estados y los estratos sociales con la sindemia.

Lo cual se define la doctora Mendenhall, (2020) como el término "sindemia" se refiere a la agrupación de dos o más enfermedades dentro de una población que contribuye a, y resulta de, las desigualdades sociales y económicas persistentes. El concepto se centra en casos en los que múltiples problemas de salud interactúan, a menudo biológicamente, entre sí y con el entorno sociocultural, económico y físico.

\section{Método}

Los métodos utilizados dentro de la investigación fueron:

Analítico que es aquel método de investigación que descompone un todo en partes para observar y entender la naturaleza del tema abordado. Este método nos permitirá analizar cada uno de los elementos que deben identificarse al considerar los conceptos jurídicos que versan la diversidad funcional e inclusiva y su impacto social. Descriptivo, que consiste en recoger, analizar, resumir, presentar los resultados de la investigación. Este último método implica la recopilación y presentación sistemática de datos para dar una idea clara de una determinada situación. En esta investigación se utilizó para conocer los antecedentes en relación de los derechos y obligaciones de cada uno de los que intervienen sociedad, estado Instituciones de educación superior a los que se han hecho mención, así como para analizar 
Año 13.

Revista de Investigación

Núm. 33

Académica sin Frontera

ISSN: 2007-8870

\section{http://revistainvestigacionacademicasinfrontera.com}

Recibido el 28 de agosto de 2020. Dictaminado mediante arbitraje favorablemente 7 de diciembre de 2020.

la evolución de las observaciones por los organismos internacionales de la materia de estudio; Deductivo, tomando como fundamento algunos principios o conocimientos generales que son aplicables para inferir conclusiones particulares en el área. De esta manera se razonarán los conceptos, de la generalidad a lo más específico.

\section{Resultados}

Dentro de los grandes avances que se han realizado en el tema de la diversidad funcional y inclusiva que se ha avanzado bastante en el estado mexicano en el sentido en la Constitución Política de los Estados Unidos Mexicanos CÁMARA DE DIPUTADOS DEL H. CONGRESO DE LA UNIÓN, (2020) manifiesta en su artículo Primero:

En los Estados Unidos Mexicanos todas las personas gozarán de los derechos humanos reconocidos en esta Constitución y en los tratados internacionales de los que el Estado Mexicano sea parte, así como de las garantías para su protección, cuyo ejercicio no podrá restringirse ni suspenderse, salvo en los casos y bajo las condiciones que esta Constitución establece.

Las normas relativas a los derechos humanos se interpretarán de conformidad con esta Constitución y con los tratados internacionales de la materia favoreciendo en todo tiempo a las personas la protección más amplia.

Todas las autoridades, en el ámbito de sus competencias, tienen la obligación de promover, respetar, proteger y garantizar los derechos humanos de conformidad con los principios de universalidad, interdependencia, indivisibilidad y progresividad. En consecuencia, el Estado deberá prevenir, investigar, sancionar y reparar las violaciones a los derechos humanos, en los términos que establezca la ley. 
Año 13.

Revista de Investigación

Núm. 33

Académica sin Frontera

ISSN: 2007-8870

\section{http://revistainvestigacionacademicasinfrontera.com}

Recibido el 28 de agosto de 2020. Dictaminado mediante arbitraje favorablemente 7 de diciembre de 2020.

Está prohibida la esclavitud en los Estados Unidos Mexicanos. Los esclavos del extranjero que entren al territorio nacional alcanzarán, por este solo hecho, su libertad y la protección de las leyes.

Queda prohibida toda discriminación motivada por origen étnico o nacional, el género, la edad, las discapacidades, la condición social, las condiciones de salud, la religión, las opiniones, las preferencias sexuales, el estado civil o cualquier otra que atente contra la dignidad humana y tenga por objeto anular o menoscabar los derechos y libertades de las personas.

Así mismo su artículo tercero nos manifiesta la igualdad en la educación priorizando el erradicar la desigualdad tal y como se desprende de sus Artículos reformados en el año 2019.

Toda persona tiene derecho a la educación. El Estado Federación, Estados, Ciudad de México y Municipios impartirá y garantizará la educación inicial, preescolar, primaria, secundaria, media superior y superior. La educación inicial, preescolar, primaria y secundaria conforman la educación básica; ésta y la media superior serán obligatorias, la educación superior lo será en términos de la fracción X del presente artículo. La educación inicial es un derecho de la niñez y será responsabilidad del Estado concientizar sobre su importancia. Corresponde al Estado la rectoría de la educación, la impartida por éste, además de obligatoria, será universal, inclusiva, pública, gratuita y laica.

La educación se basará en el respeto irrestricto de la dignidad de las personas, con un enfoque de derechos humanos y de igualdad sustantiva. Tenderá a desarrollar armónicamente todas las facultades del ser humano y fomentará en él, a la vez, el amor a la Patria, el respeto 
Año 13.

Revista de Investigación

Núm. 33

Académica sin Frontera

ISSN: 2007-8870

\section{http://revistainvestigacionacademicasinfrontera.com}

Recibido el 28 de agosto de 2020. Dictaminado mediante arbitraje favorablemente 7 de diciembre de 2020.

a todos los derechos, las libertades, la cultura de paz y la conciencia de la solidaridad internacional, en la independencia y en la justicia; promoverá la honestidad, los valores y la mejora continua del proceso de enseñanza aprendizaje.

El Estado priorizará el interés superior de niñas, niños, adolescentes y jóvenes en el acceso, permanencia y participación en los servicios educativos.

Las maestras y los maestros son agentes fundamentales del proceso educativo y, por tanto, se reconoce su contribución a la trasformación social. Tendrán derecho de acceder a un sistema integral de formación, de capacitación y de actualización retroalimentado por evaluaciones diagnósticas, para cumplir los objetivos y propósitos del Sistema Educativo Nacional.

Y en su último párrafo adicionado en el 2019 observa la inclusión en forma genérica de la educación; La obligatoriedad de la educación superior corresponde al Estado. Las autoridades federales y locales establecerán políticas para fomentar la inclusión, permanencia y continuidad, en términos que la ley señale. Asimismo, proporcionarán medios de acceso a este tipo educativo para las personas que cumplan con los requisitos dispuestos por las instituciones públicas.

La Ley General de Educación Ley publicada en el Diario Oficial de la Federación el 30 de septiembre de 2019 H. Congreso de la Union, (2019) Manifiesta en su artículo Primero; La presente Ley garantiza el derecho a la educación reconocido en el artículo Tercero. de la Constitución Política de los Estados Unidos Mexicanos y en los Tratados Internacionales de los que el Estado Mexicano sea parte, cuyo ejercicio es necesario para alcanzar el bienestar 
Año 13.

Revista de Investigación

Núm. 33

Académica sin Frontera

ISSN: 2007-8870

\section{http://revistainvestigacionacademicasinfrontera.com}

Recibido el 28 de agosto de 2020. Dictaminado mediante arbitraje favorablemente 7 de diciembre de 2020.

de todas las personas. Sus disposiciones son de orden público, interés social y de observancia general en toda la República.

Justamente en el artículo Séptimo de la ley de educación en mención; observa Corresponde al Estado la rectoría de la educación; la impartida por éste, además de obligatoria, será:

I. Universal, al ser un derecho humano que corresponde a todas las personas por igual, por lo que:

a) Extenderá sus beneficios sin discriminación alguna, de conformidad con lo dispuesto en el artículo 1o. de la Constitución Política de los Estados Unidos Mexicanos, y

b) Tendrá especial énfasis en el estudio de la realidad y las culturas nacionales;

II. Inclusiva, eliminando toda forma de discriminación y exclusión, así como las demás condiciones estructurales que se convierten en barreras al aprendizaje y la participación, por lo que:

a) Atenderá las capacidades, circunstancias, necesidades, estilos y ritmos de aprendizaje de los educandos;

b) Eliminará las distintas barreras al aprendizaje y a la participación que enfrentan cada uno de los educandos, para lo cual las autoridades educativas, en el ámbito de su competencia, adoptarán medidas en favor de la accesibilidad y los ajustes razonables;

c) Proveerá de los recursos técnicos-pedagógicos y materiales necesarios para los servicios educativos, $\mathrm{y}$ 
Año 13.

Revista de Investigación

Núm. 33

Académica sin Frontera

ISSN: 2007-8870

\section{http://revistainvestigacionacademicasinfrontera.com}

Recibido el 28 de agosto de 2020. Dictaminado mediante arbitraje favorablemente 7 de diciembre de 2020.

d) Establecerá la educación especial disponible para todos los tipos, niveles, modalidades y opciones educativas, la cual se proporcionará en condiciones necesarias, a partir de la decisión y previa valoración por parte de los educandos, madres y padres de familia o tutores, personal docente y, en su caso, por una condición de salud;

III. Pública, al ser impartida y administrada por el Estado, por lo que:

a) Asegurará que el proceso educativo responda al interés social y a las finalidades de orden público para el beneficio de la Nación, y

b) Vigilará que, la educación impartida por particulares cumpla con las normas de orden público que rigen al proceso educativo y al Sistema Educativo Nacional que se determinen en esta Ley y demás disposiciones aplicables;

En el Artículo octavo de la referida ley desprende que El Estado está obligado a prestar servicios educativos con equidad y excelencia.

Las medidas que adopte para tal efecto estarán dirigidas, de manera prioritaria, a quienes pertenezcan a grupos y regiones con mayor rezago educativo, dispersos o que enfrentan situaciones de vulnerabilidad por circunstancias específicas de carácter socioeconómico, físico, mental, de identidad cultural, origen étnico o nacional, situación migratoria o bien, relacionadas con aspectos de género, preferencia sexual o prácticas culturales.

De este modo también en su artículo Noveno de la Ley General de educación observa; Las autoridades educativas, en el ámbito de sus respectivas competencias y con la finalidad de establecer condiciones que permitan el ejercicio pleno del derecho a la educación de cada persona, con equidad y excelencia, realizarán entre otras, las siguientes acciones: 
Año 13.

Núm. 33
Revista de Investigación Académica sin Frontera ISSN: 2007-8870

\section{http://revistainvestigacionacademicasinfrontera.com}

Recibido el 28 de agosto de 2020. Dictaminado mediante arbitraje favorablemente 7 de diciembre de 2020.

I. Establecer políticas incluyentes, transversales y con perspectiva de género, para otorgar becas y demás apoyos económicos que prioricen a los educandos que enfrenten condiciones socioeconómicas que les impidan ejercer su derecho a la educación

\section{Discusión.}

Como resultado se puede inferir que las prioridades de la educación anteriormente implantadas han influido aumentando la desigualdad y la marginación de las personas, por lo que la nueva ley General de Educación promulgada en el año 2019 está acorde a las políticas de incluir las personas de diversidad Funcional y brindar educación en forma inclusiva en todos los niveles de estudio.

Por otro lado, en los planes de desarrollo institucionales de las Instituciones de Educación Superior no los observa; si bien es cierto tienen autonomía como por ejemplo de dirección, cátedra e infraestructura y principalmente en ciertos accesos físicos para las personas que cuentan con diversidad Funcional en algunas de sus unidades; no son suficientes a la demanda de nuestra actualidad.

En lo particular se ha revelado a través de estos análisis que en la mayoría de las IES no existen planes con el fin de incluir dentro de sus políticas de desarrollo La Diversidad Funcional, ya que, si bien no solo abarca a los estudiantes, sino también a las personas que laboran como maestros que por mayoría de edad van mermando sus capacidades físicas y por lo tanto tarde o temprano serán personas con Diversidad Funcional ya que más de la mitad de la planta laboral de la Universidades su edad promedio de mayor a 50 años. 


\section{http://revistainvestigacionacademicasinfrontera.com}

Recibido el 28 de agosto de 2020. Dictaminado mediante arbitraje favorablemente 7 de diciembre de 2020.

\section{Conclusiones}

1.- Se Concluye y se recomienda que las Instituciones de Educación superior observar las políticas públicas Del Plan de Desarrollo Nacional; realizar un análisis retrospectivo de sus propios planes de Desarrollo Institucionales, con el fin de impulsar una verdadera educación inclusiva, observar los conceptos de Diversidad Funcional e Inclusión crear espacios físicos de infraestructura, así como de tecnología; modificar la curricula de estudio adecuado a las necesidades especiales, con el fin de que verdaderamente existan sistemas inclusivos creando condiciones ambientales y físicas dentro de sus instalaciones .

2.- Finalmente reconociéndose que esta Sindemia del Covid 19, se han observado otros problemas de inclusión que han afectado duramente a la población estudiantil como la falta del acceso a la tecnología a los alumnos de baja capacidad económica o donde su lugar residencia que por su geografía no cuentan con acceso a internet o telefonía.

3.-También hay otros puntos de vista que se beneficiaron como alumnos que cuentan con Diversidad Funcional severa y por medio de la tecnología como TEAMS en el cual se utiliza tiene mejor acceso a estudio que como si fuera presencial, pero se destaca que son los mas aplicados en cumplir con todas las tareas que se les exigían en la materia, a lo cual se manifiestan más participativos en clases.

\section{Referencias}

H. Congreso de la Union. (30 de Septiembre de 2019). Ley General de Educación. Ley General de Educación. México, México, México: Diario Oficial de la Federacion.

ROMAÑACH , J., \& MANUEL, L. (14 de Enero de 2018). Dianet. Obtenido de dianet: SUPERIOR/Dialnet-DiversidadFuncional-2393402.pdf 
Año 13.

Revista de Investigación

Núm. 33

Académica sin Frontera

ISSN: 2007-8870

http://revistainvestigacionacademicasinfrontera.com

Recibido el 28 de agosto de 2020. Dictaminado mediante arbitraje favorablemente 7 de diciembre de 2020.

CÁMARA DE DIPUTADOS DEL H. CONGRESO DE LA UNIÓN. (14 de Octubre de 2020). $H$. CONGRESO DE LA UNIÓN. Obtenido de H. CONGRESO DE LA UNIÓN:

http://www.diputados.gob.mx/LeyesBiblio/pdf/1_080520.pdf

Conferencia Mundial Sobre La educación Superior. (5 de Octubre de 1998). Educación siglo XXI UNESCO. Obtenido de Educación siglo XXI UNESCO:

http://sigc.uqroo.mx/Documentos\%20Externos/Educacion\%20Siglo\%20XXI\%20UNESCO .pdf

Mendenhall, E. (20 de Septiembre de 2020). Intra Med. Obtenido de Intra Med: https://www.intramed.net/contenidover.asp?contenidoid=90525

Naciones Unidas . (5 de Diciembre de 2015). NACIONES UNIDAS- Personas con Discapacidad. Obtenido de NACIONES UNIDAS- Personas con Discapacidad: https://www.who.int/disabilities/world_report/2011/summary_es.pdf?ua=1

Nahum Montagud, R. (10 de 10 de 2020). Psicología y Mente. Obtenido de Psicología y Mente: https://psicologiaymente.com/salud/tipos-de-diversidad-funcional

Organización Mundial de la Salud. (2011). Resumen del Informe Mundial sobre la Discapacidad. Malta: Organización Mundial de la Salud. 
"Fl whiser ite mis hijos

Año 13.
Revista de Investigación

Académica sin Frontera

ISSN: 2007-8870

http://revistainvestigacionacademicasinfrontera.com

Recibido el 28 de agosto de 2020. Dictaminado mediante arbitraje favorablemente 7 de diciembre de 2020.

\section{Directorio Institucional}

Dr. Enrique Fernando Velázquez Contreras

Rector

Dr. Ramón Enrique Robles Zepeda

Secretario General Académico

Dra. Rosa María Montesinos Cisneros

Secretaria General Administrativa

Dr. Rodolfo Basurto Álvarez

Director de Vinculación y Difusión

Dra. Adriana Leticia Navarro Verdugo

Vicerrectora de la Unidad Regional Sur

Dr. Ernesto Clark Valenzuela

Director de la División de Ciencias Económicas y Sociales

Dr. Francisco Espinoza Morales

Secretario de la División de Ciencias Económico y Sociales

Dra. Leticia María González Velásquez

Jefe del Departamento de Ciencias Económico Administrativas

Dra. Lidia Amalia Zallas Esquer

Jefe de Departamento de Ciencias Sociales 
Año 13.

Revista de Investigación

Núm. 33

Académica sin Frontera

ISSN: 2007-8870

http://revistainvestigacionacademicasinfrontera.com

Recibido el 28 de agosto de 2020. Dictaminado mediante arbitraje favorablemente 7 de diciembre de 2020.

\title{
Comité Directivo
}

\author{
Editor Responsable \\ Dr. Francisco Espinoza Morales \\ Universidad de Sonora \\ Directora \\ Dra. Leticia María González Velásquez \\ Universidad de Sonora \\ Subdirector \\ Dr. Javier Carreón Guillen \\ Universidad Nacional Autónoma de México \\ Editor Científico \\ Dr. Cruz García Lirios \\ Universidad Autónoma del estado de México \\ Master Gráfico \\ M.T.I. Francisco Alan Espinoza Zallas \\ Universidad Estatal de Sonora
}

Nos complace anunciar que su diario, "Academic Research Journal Withoutborders" (ISSN/EISSN 2007-8870) fue evaluado positivamente en la indexación Citefactor, ahora la página de la revista está disponible en línea, en caso de cualquier problema.

Journals Master | International Innovative Journal Impact Factor (IIJIF)

Red Latinoamericana de revistas Académicas en Ciencias Sociales y Humanidades
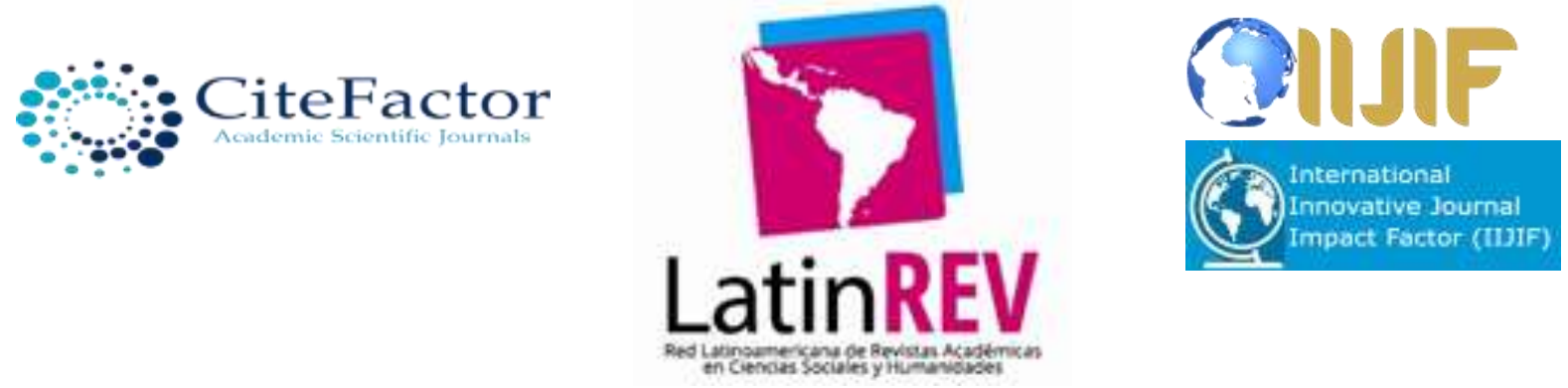
Año 13.

Revista de Investigación

Núm. 33

Académica sin Frontera

ISSN: 2007-8870

http://revistainvestigacionacademicasinfrontera.com

Recibido el 28 de agosto de 2020. Dictaminado mediante arbitraje favorablemente 7 de diciembre de 2020.

\section{Comité editorial}

Dra. Angélica María Rascón Larios

Universidad de Sonora. México

Dra. María del Rosario Molina González

Universidad de Sonora

Dra. Francisca Elena Rochin Wong

Universidad de Sonora. México

Dra. Lidia Amalia Zallas Esquer

Universidad de Sonora. México

Dra. Beatriz Llamas Arechiga

Universidad de Sonora. México

Dr. Rogelio Barba Álvarez

Universidad de Guadalajara. México

Dra. Rosa María Rincón Ornelas

Universidad de Sonora. México

Dr. Juan Flores Preciado

Universidad de Colima. México

Dr. Amado Olivares Leal. Universidad de Sonora

Universidad de Sonora. México

Dr. Guillermo Velázquez Valadez.

Instituto Politécnico Nacional (IPN) México

Dr. Hugo Nefstalí Padilla Torres.

Universidad Estatal de Sonora. México

Dr. Luis Ramón Moreno Moreno.

Universidad Autónoma de Baja California. México

Dr. Miguel Ángel Vázquez Ruiz.

Universidad de Sonora. México 


\section{http://revistainvestigacionacademicasinfrontera.com}

Recibido el 28 de agosto de 2020. Dictaminado mediante arbitraje favorablemente 7 de diciembre de 2020.

Dra. Lorena Vélez García.

Universidad Autónoma de Baja California. México

Dra. Pabla Peralta Miranda.

Universidad Simón Bolívar, Barranquilla, Colombia

Mtro. Roberto Espíritu Olmos

Universidad de Colima (FCA Tecomán) Colima

Dr. Héctor Priego Huertas.

Universidad de Colima (FCA Tecomán) Colima

Mtra. María Guadalupe Alvarado Ibarra.

Universidad de Sonora. México.

MSc. Celso Germán Sánchez Zayas

Universidad de Camagüey, Ignacio Agramonte Loynaz, Cuba

Dra. María Luisa Quintero Soto

Universidad Autónoma del Estado de México

Dr. Eyder Bolivar Mojica

Universidad Católica, Luis Amigó, Medellin, Colombia

Revisores de Textos en Inglés

Mtro. Renato Encinas

Mtra. Cecilia Guadalupe Martínez Solano

\section{Comité científico}

Dr. Rosendo Martínez Jiménez. Universidad Autónoma Benito Juárez de Oaxaca.

Dr. Hugo Neftalí Padilla. Universidad Estatal de Sonora

Dra. María Teresa Gaxiola Sánchez. Universidad de Sonora.

Dr. José Cesar Kaplan. Universidad Estatal de Sonora.

Dr. Alfredo Islas Rodríguez. Universidad de Sonora

Frecuencia de publicación: semestral / 2 números por año. 


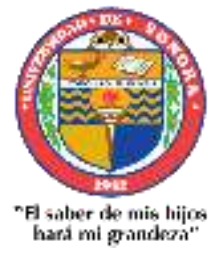

( Julio - Diciembre 2020)

Año 13.

Núm. 33

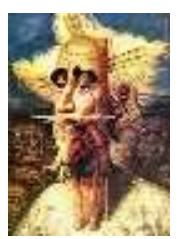

Revista de Investigación Académica sin Frontera

ISSN: 2007-8870

http://revistainvestigacionacademicasinfrontera.com

Recibido el 28 de agosto de 2020. Dictaminado mediante arbitraje favorablemente 7 de diciembre de 2020.

Revista de Investigación Académica sin Frontera (RIASF) con (ISSN: 2007-8870) es un interlocutor internacional de acceso abierto revisado diario en línea en el ámbito del de las Ciencias Económicas Administrativas y Sociales. Su objetivo principal es dar a los trabajos de investigación de calidad. Cubre todas las sub-campos de los campos anteriormente mencionados. Proporciona la plataforma a académicos, estudiantes y profesionales. Sólo pública trabajos de investigación y artículos de revisión inicial. Documento presentado debe cumplir con algunos criterios como, debe ser original, inédita y no estén sometidos a ninguna otra revista.

RIASF es una revista arbitrada / Revisión por pares International. Publicamos documentos sobre una variedad de temas, contextos y estrategias de análisis que examinan la relación entre la rápida evolución para la Sociedad y la tecnología del conocimiento.

REVISTA DE INVESTIGACIÓN ACADÉMICA SIN FRONTERA, Año 13, No. 33, Julio - diciembre 2020, es una publicación semestral de investigación científica, editada por la Universidad de Sonora, a través de las División de Ciencias Económicas y Sociales, de la Unidad Regional Sur, Blvd. Lázaro Cárdenas No. 100, Col. Francisco Villa, Navojoa, Sonora, Sonora, México, C.P. 85880. Tel. (642) 42599-54.

http://www.revistainvestigacionacademicasinfrontera.com/, revistaacademicasinfrontera@ unison.mx. Editor responsable: Francisco Espinoza Morales. Reserva de Derechos al Uso Exclusivo: 042013-121811323700-203 e ISSN: 2007-8870, ambos otorgados por el Instituto Nacional de Derecho de Autor. Inscrita en el Directorio de LATINDEX, con Núm. De folio 20014, folio único 14590. Responsable de la última actualización de este Número, Unidad Informática de la Universidad de Sonora, fecha de la última modificación, 30 de diciembre 2020, indexada a Cite Factor Academic Scientific Journal y Journals Master (IIJIF) y Red Latinoamericana de Revistas Académicas en Ciencias Sociales y Humanidades, (Latín Rev). Las opiniones expresadas por los autores no necesariamente reflejan la postura del editor de la publicación. Se autoriza la reproducción total o parcial de los contenidos e imágenes en la presente publicación siempre y cuando se cuente con la autorización del editor y se cite plenamente la fuente. 
Año 13.

Revista de Investigación

Núm. 33

Académica sin Frontera

ISSN: 2007-8870

http://revistainvestigacionacademicasinfrontera.com

Recibido el 28 de agosto de 2020. Dictaminado mediante arbitraje favorablemente 7 de diciembre de 2020.

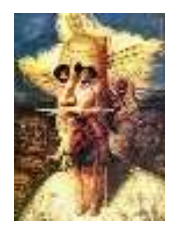

Nos complace anunciar que su diario, "Academic Research Journal Withoutborders" (ISSN/EISSN 2007-8870) fue evaluado positivamente en la indexación Citefactor, ahora la página de la revista está disponible en línea, en caso de cualquier problema.

Journals Master | International Innovative Journal Impact Factor (IIJIF)

\section{Red Latinoamericana de revistas Académicas en Ciencias Sociales y Humanidades}
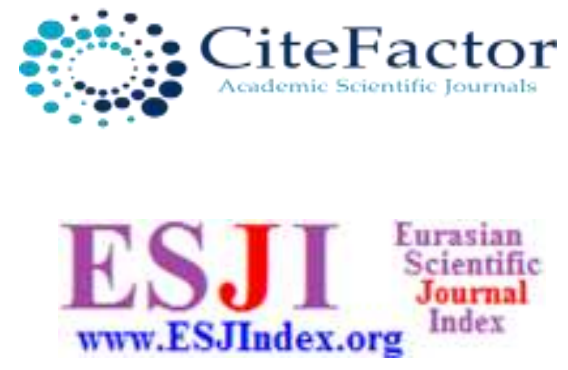

https://www.neliti.com

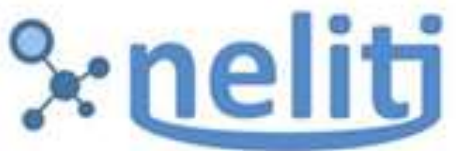

Indonesia's Research Repository

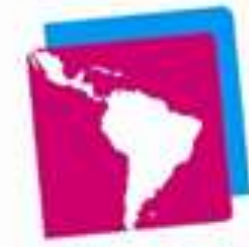

LatinREV
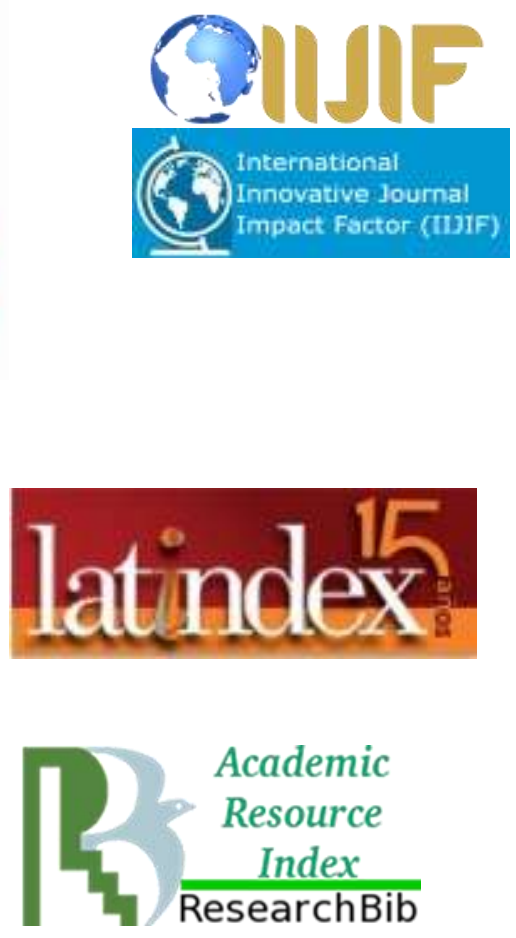